\title{
4 Exploring the Importance of Teacher Feedback
}

\section{Connecting Truthfulness and Student Learning}

\author{
Jeff Frank
}

Feedback is central to teaching and learning, and yet feedback's central role doesn't receive a great deal of attention in the philosophical literature in education. ${ }^{1}$ This is unfortunate because a teacher will not develop into the teacher they hope to become unless they devote significant attention to the role that feedback plays in their teaching practice. In the first part of this paper, I explore the centrality of feedback in teaching and learning, largely through a conceptual analysis of how feedback operates in classrooms. In the second part, I explore the connections between a teacher reflecting on feedback and their teaching practice, largely by drawing on Bernard Williams's thinking on truthfulness. Finally, in the third part of the paper, I suggest that a teacher who is thoughtful about their approach to feedback is in a better position to promote deeper learning than a teacher who is not. I conclude with recommendations for teacher education and teacher professional development. ${ }^{2}$

As other chapters in this volume make clear, it is imperative that we understand what accounts for gaps in performance between classrooms that are deemed high-performing and those that are deemed low-performing. While countless explanations of this gap have been offered in the literature ${ }^{3}-$ everything from teachers holding lower expectations for students, to assuming a deficit perspective when thinking about the students and their home culture(s), to providing instruction that fails to engage and appropriately challenge students - what connects all of these explanations is the significance of the teacher's intervention to close existing gaps. In this chapter, I suggest that the use of truthful feedback is a key element in appropriately challenging and educating every student, and I also suggest that this is something that a teacher has control over, even in an era marked by standardisation of curriculum and assessment.

Thinking about feedback is important, because it offers us a lens to view the ends of education in a new light (Harðarson, 2012, 2018). As schools, principals and teachers come under exceeding pressure to increase student performance, we need a better understanding of the purposes of education so that we don't narrow the ends of education and demoralise teachers (Santoro, 2018). When we consider the uses of feedback in the classroom, we are given an opportunity to theorise the purposes of education in ways that invite

DOI: $10.4324 / 9781003218067-4$ 
us to consider how feedback can give teachers increased agency to engage in the type of teaching that they value and that promotes deeper learning for their students. And when we do this, teachers can more wholeheartedly stand behind their teaching practice, which will have the saltatory effect of re-moralising teachers while increasing the learning and engagement of students. This offers one way of closing the gaps between high- and low-performing schools without sacrificing our values and ideals in the process.

\section{The Role of Teacher Feedback in the Life of Classrooms}

Philip W. Jackson's (1990) Life in Classrooms remains remarkable for its ability to draw a reader's attention to those everyday aspects of classroom life that evade notice and critical attention, precisely because they are so commonplace. One aspect of classroom life that often escapes attention is the ubiquity of feedback a teacher offers. Especially in the early years of a child's life in school, teacher feedback is omnipresent. Sit there, sit like that, don't talk, colour like this, don't say that, listen, eyes up here, the blocks go like that, that book isn't on your level, choose another, and so on. Though much of a teacher's feedback is spoken, much isn't. A teacher points, a teacher raises an eyebrow, a teacher throws their hands up, a teacher frowns, a teacher beams with encouragement, and a teacher glares. Finally, students receive feedback that the teacher may not intend or be fully in control of. A teacher's disapproval based on a student's social position or identity category feeds back into a student's sense of welcome, belonging or acceptance in the classroom, and this impacts their sense of agency and engagement.

Already we can begin to see the centrality of feedback in the life of a classroom, along with important distinctions. Some feedback is about learning, some is about behaviour. Some feedback is explicit and spoken, while some is implied and unspoken. Feedback can be biased, and teachers can unintentionally communicate approval or disapproval in explicit and implicit ways. Though biased feedback may not be intended by the teacher, it has power nonetheless. A teacher's dismissive glance at a group of young girls during math time may communicate that boys are more capable when it comes to math. Praising one child's jacket or new outfit may alienate the child in a second-hand coat.

It is important to consider another level of analysis. Some feedback is formal. Students receive comments on their work along with grades. Children receive comments on their report cards, also often accompanied by grades. As well, teachers facilitate assessments that they didn't create - everything from daily diagnostic computer work (Frank, 2020) to standardised tests but they communicate the results of those assessments to students and their caregivers and use these assessments when planning instruction.

Finally, it is common to talk about assessment of learning, versus assessment for learning, versus assessment as learning (Earl, 2003). These distinctions often track onto distinctions between formative and summative assessment, and they also track onto discussions of authentic assessments, high-stakes 
assessments and standardised assessments. The key point in all these distinctions is to help get clear on the ways that assessment is primarily intended to measure or account for learning, and when assessment is meant to promote, deepen and extend learning.

This discussion and these distinctions are not meant to suggest that a philosopher of education, using conceptual analysis, can resolve problems of practice from their armchair. Rather, the foregoing analysis is meant to suggest that these different senses of feedback are deeply interconnected and that it is useful for a teacher to work to get clear - for themselves - how feedback works in their classroom.

To take up one key distinction, it is often very useful for a teacher to consider which assessments and standards originate outside of their classroom, and then think about how important those standards and assessments are to their sense of what it means to be a teacher. A related point: it is also often important for a teacher to understand how circumscribed their freedom is when it comes to what must be taught and what types of assessment must be administered. A set of standards connected to a standardised test is not a curriculum, let alone a script, but they are often taken that way (Wiggins \& McTighe, 2005). Put another way, two teachers can use the same set of standards and have their students achieve high scores on a mandated standardised test but get to that goal in very different ways. One teacher can spend a great deal of time encouraging memorisation and doing test preparation, while another teacher can promote deeper learning that leads to passionate engagement and an ongoing interest in the material learned (Martinez \& McGrath, 2014; Mehta \& Fine, 2019).

A key difference in these classrooms is the way a teacher uses feedback to express what is valued. In the test preparation classroom, a teacher's feedback will often be closely tied to outcomes. In the deeper learning classroom, teacher feedback will be tied to the process of engagement and will encourage thinking (Ritchart, 2015). What is equally important is that a teacher's behavioural feedback will also often be tied to their instructional goals. In a classroom where memorisation is prized, one set of behaviours will be cultivated. In a classroom where thinking is the goal, other behaviours will be nurtured.

This discussion may feel a bit too abstract and disconnected to the complexities of practice (Lampert, 2001). The point, though, is to suggest that teachers become as mindful as possible about the scope of their freedom so that they can think about their hopes for the work of teaching. Unless a teacher is aware of the type of practice they hope to enact in their classroom and through their work, it is far more likely that the feedback the teacher uses will be the product of history and habit, not something that the teacher very intentionally uses to create the type of classroom environment that they are genuinely proud of and that stands up to their own sense of what a classroom should be and do.

To summarise, feedback is ubiquitous and multifaceted in every classroom. A teacher is always already giving feedback, even if they aren't fully 
aware of this fact. Ignoring a student or not doing something is still expressive and plays a role in communicating who, how and what a teacher values. In classrooms where there are strong external pressures in the form of mandated curriculums, mandatory assessments and zero-tolerance discipline policies, the type of feedback a teacher provides is heavily constrained. In a culture marked by structural injustices, teachers are often unaware of their own biases and the ways that these biases impact the types of feedback they give to students and what this feedback communicates (Harber et al., 2019).

It is for these reasons that teachers need to devote significant attention to the place of feedback in their classroom, working to discover the types of constraints they face and freedom they have, while also undertaking to unlearn ways of thinking and being that are biased and harmful to their students (Cochran-Smith, 2000). This work is difficult, because it touches on who the teacher is as a person (Hansen, 1993, 2018), and the work is often moral, epistemic, and political at the same time (Frank, 2013). As such, developing an approach to feedback is something each teacher must do for themselves. Though recommendations are useful, what is ultimately needed is for each teacher to develop an orientation to giving feedback that is aligned with their own sense of teaching and its values while also remaining responsive to everything that challenges those values. In the next section, I make the case that Bernard Williams's thinking on truthfulness provides resources that teachers might draw on as they develop this orientation to their work.

\section{Truthfulness and Teacher Development}

In this section, I don't offer a detailed discussion of Bernard Williams's (2002) increasingly relevant book Truth and Truthfulness, let alone attempt to offer an overview of his work as a philosopher (Fricker, 2020). Instead, my goal is more modest. I am interested in discussing the importance of truthfulness when it comes to providing feedback, where truthfulness is understood in terms of accuracy and sincerity. Both Shirley Pendlebury (2008) and David Cooper (2008) discuss the importance of accuracy and sincerity for teaching, but neither connect their discussions to a teacher's orientation to offering feedback.

I turn to Williams in this paper because I believe that a spirit of truthfulness is at risk, especially in the United States. Many Americans continue to believe - despite overwhelming evidence - that Donald Trump won the 2020 Presidential election in a 'landslide.' What is worse, they were willing to attack America's Capitol based on this false belief. As well, many Americans engage in conspiracy thinking, even about things as tragic as school shootings that leave families and communities utterly devastated. Bernard Williams is well aware that asserting something as truth isn't simple, especially in a world learning the lessons of standpoint theory and responsive to neo-pragmatist and postmodern approaches to truth. Subjectivity and bias will certainly colour our best attempts at objectivity and truth, but this doesn't mean that any opinion or assertion is as good as any other or that it is impossible to assert 
matters of fact like who won a contested election. We don't need a simplistic approach to truth in a post-truth era, and this is not what Williams offers. Instead, Williams suggests that the best hope for truth is to cultivate a spirit of truthfulness, where truthfulness is an aspiration guided by the virtues of sincerity and accuracy.

To understand truthfulness, we need to understand these two virtues. Williams describes sincerity as saying what one means, and accuracy as accepting reality as a check on one's beliefs, especially in cases where reality challenges beliefs that one sincerely holds. In our time, especially in the United States, I worry that we are alienated from the virtues of sincerity and accuracy. Schools, for example, are often so focused on 'getting results' and pursuing success very narrowly understood (Frank \& McDonough, 2020), that questions of sincerity don't even arise. When external measures of success are pursued, or when we don't even wonder about the difference between success as defined by others and success as we take it to be (Siegel \& Bryson, 2018), it is extraordinarily difficult to act with sincerity. And while most schools still aspire to the virtue of accuracy, they are embedded in cultures that are flooded with disinformation (Rauch, 2020). More, there are individuals who are so invested in their preferred vision of reality that they'd rather cling to that false vision rather than acknowledge or accept any truth that challenges their beliefs. As such, even though schools may aspire to accuracy, teachers may find it challenging to teach in a spirit of truthfulness when embedded in a community that is often wilfully living in misbelief (Buchanan, 2018).

The virtues of sincerity and accuracy are as important as they are at risk in our time, and there are many ways to use Williams's insight to think about education. ${ }^{4}$ In this paper, I narrow my focus to truthfulness and feedback, and I begin by exploring the opposite of truthful feedback. We might think of feedback that lacks truthfulness as feedback that is insincere and inaccurate. Feedback is insincere when it doesn't connect to meaningful learning goals. For example, if I am teaching to a test and not teaching something that I genuinely think is valuable for students to learn, much of my feedback is likely to be inauthentic. Feedback is inaccurate when it is misleading. If I lower standards for some children - either intentionally or through unconscious bias - and assert that their work is strong when it is not, I provide inaccurate feedback. In my experience, I see teachers struggling with authenticity and accuracy, and one hope for this paper is that it offers teachers ways of reclaiming both virtues so that they might provide more truthful feedback.

To take a step in this direction, I want to offer a concrete example of moving from standards to feedback. For the purposes of this paper, I will draw on my own experience as a teacher educator, and I will use the framework of Understanding by Design, a common approach to instructional design in the United States. The selection of Understanding by Design is not as important as the way it helps us think through the process of moving from instructional goals to assessment, and finally to instruction (Wiggins \& McTighe, 2005). ${ }^{5}$ The first stage of Understanding by Design asks a teacher 
to specify their learning goals. Though many teachers have external standards they must be responsive to, they generally have freedom in how those standards get translated into goals. In the United States, the Common Core Standards have generated a great deal of controversy. I sidestep that controversy, and - instead - use a Common Core Standard to illuminate what I mean by teacher instructional freedom. Here is a grade 9-10 standard from English Language Arts, specifically reading literature:

\section{CCSS.ELA-LITERACY.RL.9-10.9}

Analyze how an author draws on and transforms source material in a specific work (e.g. how Shakespeare treats a theme or topic from Ovid or the Bible or how a later author draws on a play by Shakespeare). ${ }^{6}$

As you can see, the standard is under-determined. While schools or states may specify which texts must be taught or which source material must be used, in many cases a teacher will have a great deal of freedom when it comes to how to interpret the standard. Here accuracy and sincerity come into play. A teacher must accurately interpret what the standard is asking, but they also must sincerely consider how the standard speaks to them as a teacher of their particular students, in their particular context at this particular time in history. So long as the teacher is accurately interpreting the standard, they have freedom to teach from their own passions and interests and what they take their students' passions and interests to be.

This may not seem to immediately connect to feedback, but it does. The teacher who takes the time to accurately and sincerely reflect on the purposes of the standard is in a better position to respond to the student question, often unasked: Why does this matter? Why do I need to learn this? A teacher who takes the time to accurately and sincerely interpret the standard is positioned to wholeheartedly get behind their teaching and send the message - explicitly and implicitly - that they are teaching something that matters, both because it meets the external learning standards and because it speaks to something the teacher cares about or believes students do - or should - care about.

In the case of the Common Core Standard discussed earlier, you can imagine a teacher picking several poems they care about that draw from a shared source material and then you can also imagine them using those poems to get students excited about poetry and the message the source material is trying to convey. Now, there may be schools and states that take away a teacher's freedom in relation to standards, and this may lead a teacher to seek another place to teach or to exit the profession completely (Santoro, 2011). But in many cases, the freedom to interpret standards exists, and when it does, teachers can think through what it means to accurately and sincerely interpret their standards in ways that make them meaningful for students.

Stage two of Understanding by Design is moving from standards to planning assessment. Here, again, the teacher is mindful of the external tests their students are mandated to take, just as they will think about the types 
of assessments that are most responsive to their own sense for what is most interesting and important about the standard. Where one teacher may simply have students practice examples of the type of external assessments they will take, another teacher will use their most truthful interpretation of the standard to create assessments aligned with that interpretation. For example, a teacher may give students source material from the New Testament, and then have them read speeches by Martin Luther King, Jr. or the non-fiction of James Baldwin or the fiction of Toni Morrison, asking the student to find examples of how these works respond to or modify the source material in ways that the student finds most meaningful or interesting. Or the teacher can have students work in the other direction. They can provide contemporary literature that draws on source material and have the students find and engage with the source material in order to understand the contemporary literature and the source material. A key distinction I am trying to make clear is that the assessments can be mechanical and relatively unthinking, or assessments can call on students to engage and think more deeply. A teacher who gives a list of Bible verses or Shakespeare plays and has students draw a line or fill in a bubble to connect the literature that uses the source material is giving an assessment that is responsive to the standard but that doesn't ask the students to think. By contrast, a teacher who has students find material on their own that is responsive to source material, or who engages deeply with the source material so that students can see that source material at work in contemporary material, is using assessment to prompt and deepen thinking.

Here we can also see how feedback becomes more or less truthful. A teacher who has students match source material to a specific work is generally - only going to tell a student: that is right, that is wrong. There is less room to have a conversation. By contrast, a teacher who uses assessment to promote thinking invites students into conversation. These teachers are interested in the types of source material that connects with students, and they use feedback to connect students from the source material to specific works that the students may find interesting. Feedback in this classroom is about connections and draws on the virtues of truthfulness. Is the student accurately connecting source material to specific works, and are they sincerely interested in the connections they are making? A whole world of feedback opens in these types of classrooms, and this feedback serves to deepen thinking and engagement.

This brings us to the third stage of Understanding by Design, instruction. Once a teacher interprets the standard and uses this interpretation to develop assessments that are accurately and sincerely aligned with the standard, they develop learning opportunities that position students to be successful on the assessments. Again, if a teacher simply gives students an assessment that looks like what the student will see on a standardised test, feedback often comes in the form of judgment: this is right, this is wrong. Learning opportunities are designed so that more students are right than wrong. By contrast, when teachers design assessments that are meant to promote thinking, the teacher is less in the role of a judge and more in the 
role of conversation partner (Lear, 2009). The feedback the teacher provides works on the levels of accuracy and sincerity. The teacher wants the students to find things that allow them to think deeply and accurately about complex ideas that don't admit of simple right and wrong answers. In addition, the teacher wants students to care about what they are reading, and the teacher wants students to develop their own tastes and interests. Instead of having every single student meet the standard by showing how Martin Luther King, Jr. complicates and extends ideas from the New Testament, these teachers want students to find source material that speaks to them and contemporary works that also engage their interest. To get to this type of classroom, the teacher appreciates the ways feedback can draw students closer to the material they are learning while empowering students to embrace their developing interests and passions.

There is always room to think more intentionally about the types of learning we hope to facilitate and then think about how we can get there through our feedback. In order to do this, we might engage in a process like Understanding by Design, or any process that allows us to think deeply about our instructional goals. Importantly, just as standards can become overly determinative, even something like assessment for learning can become constraining if a teacher isn't mindful of the differences between deeper learning and something like learnification, where the sole goal of teaching is to get results (Biesta, 2010, 2012).

When I think about what makes my life as a teacher fulfilling, I often find myself reflecting on the role that feedback plays in my practice. Feedback is at the centre of my teaching because I see it as key to setting a conversational tone that allows students to make connections that open new interests and opportunities for learning. For example, I have my students write response papers so that I can write feedback that honours their current interests while drawing connections to my subject that I hope they will become interested in. I try to do the same thing in the classroom. I ask questions or do activities that - when effective - provoke student questions that suggest new lines of interest and inquiry that are true to the subject I teach and resonant with a student's genuine interests. In this way, I see feedback as a key path to meaningful teaching and deeper learning, but I think a teacher will only see feedback in this light if they are given opportunities to critically reflect on the type of teacher they hope to become, while considering the role feedback plays in developing into this teacher. When feedback is limited to correcting students and pointing them to the one correct response, possibilities of teaching and learning are also limited. By contrast, when feedback invites a conversation between teacher, student, and subject matter, teaching and learning become exciting and expansive. ${ }^{7}$

It is this expansive vision of teaching and learning that called many of us to the work of being a teacher (Hansen, 1995), and in the next section, I look at the mutually deepening connection between a commitment to accurate and sincere feedback and a commitment to promoting deeper engagement and thinking in the classroom. Seeing our classroom as a place 


\section{Jeff Frank}

of conversation and connection will transform how we see the purposes of learning and feedback, and this - in turn - will allow us to reflect on what we hope our classroom to become and how feedback will move us closer or further away from that hopeful vision.

\section{Feedback and Deeper Learning}

The previous two sections highlight how interconnected everything is in a classroom. A teacher who wants to encourage deeper thinking on the part of students needs to rethink curricular goals, assessment, instructional practices, and much else. Everything hangs together, and changes in one aspect of classroom practice have a ripple effect. Once a teacher begins to think about standards in terms of accuracy and sincerity, they come to see how many things would need to change in order for an ethos of curricular truthfulness to take root. While this can make changes to instructional practice feel impossibly complex, I also find this realisation can be empowering. That is, one realises that conditions don't need to be perfect in order to start the process of change. Rather, if a teacher begins changing one or two aspects of their practice, then other aspects of their practice will slowly change with it. Again, instead of feeling as if one must wipe the slate clean or have everything in order, a teacher can choose an aspect of their teaching practice to work on, knowing that this will eventually ripple out to touch all aspects of their classroom.

This is especially the case when we think about truthfulness and feedback. A teacher who aims to give truthful feedback to students - that is, feedback that is both accurate and sincere - realises that so much would need to change in order for them to provide this type of feedback. When an assignment is poorly constructed, it is hard to give meaningful feedback. When an assignment is too easy or disconnected from student interests or content worth engaging with, a teacher will often find it hard to give good feedback.

By contrast, when a teacher starts with the type of feedback they want to give, this can help them design meaningful work for students. For example, if I want to be able to point students in the direction of interesting readings, or make interesting connections through my feedback, the assignments I give must be open-ended enough to facilitate this type of feedback. If I give an assignment where only one correct answer is possible, it is often much harder to provide conversation-continuing feedback. But if I choose assignments where I look forward to seeing where students take their work, then I am in a position to suggest new areas of inquiry and provide feedback that draws them closer to my content area or the main themes of my course.

What I am looking to create is a virtuous cycle. When I picture the type of conversation I want to provide in my feedback, this allows me to think deeply about the type of work I need to facilitate for my students. As I become more mindful of the type of student thinking and engagement I hope to promote, I find that the quality of student work increases. Students become more engaged and more thoughtful. When this happens, the quality of my own 
feedback to students can improve. I can ask them better questions, and this helps them think more deeply. This - in turn - allows us to have better conversations in class, and it also allows me to learn more about what students are interested in and how I can connect this to my curriculum.

There is a great deal of attention being devoted to moving away from the 'game of school' and to the promotion of deeper learning (Mehta \& Fine, 2019), and I see feedback as key to promoting the goals of deeper learning. What may be even more important, feedback is something that a teacher is largely in control of. Though they may be given standards, and though their success as a teacher may be tied to the results of standardised tests given to their students and that are outside of the teacher's control, teachers can become more mindful of the type of feedback they want to provide students. As they think about the freedom they have to provide feedback they can sincerely get behind, they can also think about the type and quality of feedback they currently provide, and how they might alter that feedback so that it promotes student thinking and engagement. Once they begin doing this, they are positioned to see the ways that changing their relationship to feedback touches on all aspects of their classroom life. When they begin to think about offering feedback as facilitating a conversation, then they will rethink their learning goals, their assessments, and their instructional practices.

I don't want to suggest that any of this is simple, but I do see this process as initiating a virtuous cycle. When teachers think about the quality of the conversation they hope to facilitate through their feedback, they begin providing students work that allows this conversation to happen. When students learn how interested they are in having these types of conversations, it calls on the teacher to provide deeper learning experiences that allow them to provide even more truthful and meaningful feedback. I would like to believe that when teachers are given the space and opportunity to consider this fact, they will be motivated to start small and begin the process of taking stock of all of the ways that feedback does and doesn't work in their classroom. And when they do this, they are on the path to promoting deeper learning for their students. Giving teachers that space and opportunity is what I turn to in my conclusion.

\section{Conclusions: The Role of Feedback in the Education of Teachers}

In this conclusion, I briefly suggest and sketch out one way of promoting critical reflection on feedback as a means to cultivating student engagement and thinking while also allowing teachers to teach in ways that are responsive to their vision of what good teaching should be and do. I believe reflecting on feedback should begin in teacher education programs, and it should receive increased emphasis in teacher development.

I don't think focusing on feedback is a simple solution or a panacea, but I believe that giving teachers an opportunity to focus on feedback in their 
classroom will allow them to start the work of slow improvement right away. Here are some steps that they might take:

- Do a feedback inventory. Try to describe - though not yet judge - all the feedback given in a week.

- After listing all the feedback, code the feedback as positive, negative, neutral, using the standards of student engagement and thinking, along with a teacher's own vision of good practice, as guides.

- Begin mapping out steps that one can take to give better feedback, drawing on ideals of accuracy and sincerity.

- Critically reflect on how to make this a continuous process and a virtuous cycle.

- Look for ways to connect with other teachers, forming professional learning communities focused on feedback and doing instructional design that leads to feedback that promotes deeper learning.

Teachers can start this work in their teacher education program. They can describe all the ways that feedback works in the classrooms they observe, and then they can also think about what they would do - when they have their own classroom and during student teaching - to make feedback work for students and given their developing vision of what good practice looks like. Getting in the habit of reflecting on feedback from their teacher education program will help them stay in this habit - and advocate for its importance once they become teachers.

Of course, changes at the policy level and changes in how teachers are evaluated and supported by school leaders will make it easier for teachers to do their work well, but one of the main reasons I focus on feedback is because teachers often have room to improve this aspect of their practice almost immediately. Simply asking the question - Is this the type of feedback I want to give; does it work for students and my own vision of teaching? can be the start of a slow but rewarding transformation. For example, when I realised that the written comments I gave to my students were valued by my students more than almost any other aspect of my instructional practice, I devoted as much time as possible to giving accurate and sincere feedback. When I did this, students shared more in their response papers, and this allowed me to adjust my instruction and feedback so that it was more responsive to what my students were interested in. ${ }^{8}$ Most important, it helped me promote what I valued in the classroom: student engagement and thinking. Focusing on feedback allowed me to facilitate connections between my students and my subject area, and for this reason I think it is worthwhile to give teachers opportunities to reflect on the role of feedback in their classrooms. Again, this isn't a simple solution or a panacea, but I think it offers one path to improvement that teachers can immediately begin walking down.

Returning to a theme of the opening section, teachers need to be mindful of their unintentional biases when providing feedback. Feedback is a place where we can welcome students or make them feel as if they don't belong 
(Frank, 2021). It is important to realise that even if one intends to provide supportive and honest feedback, what matters is that a student receives the feedback in that spirit. ${ }^{9}$ In a society marked by structural injustices, teachers need to be especially mindful of how students interpret their feedback. As well, a teacher needs to balance sincerity - what they are genuinely interested in - with a sense of accuracy. When it comes to structural injustices, this means selecting material that resonates with the truths of how their students experience the world. It is too easy for a teacher to select material that they find important or interesting, assuming that this will have universal appeal. Luckily, if teachers provide students with opportunities for genuine thinking, and create a trusting environment where students feel comfortable speaking accurately and sincerely, then they will learn when they need to modify their curricular material and instructional activities. Importantly, this doesn't mean cancelling or rejecting anything, though it does mean a willingness to listen and think together about the truth. When feedback is grounded in a spirit of truthfulness, it is far more likely that these necessary conversations will happen. And it is these types of conversations that we need now, and it is these types of conversations that will make classrooms lively and engaging places that have the potential to transform students, teachers, and our world for the better.

\section{Notes}

I I argue the point here, but in one might consult Biesta and Stengel's (2016) wonderful and very comprehensive handbook chapter on the philosophy of teaching. In this handbook, chapter feedback is not discussed, and formative assessment is not a focus. Though philosophers of education are critical of assessment practices (Egelandsdal \& Riese, 2020; Rømer, 2019), philosophically informed approaches to feedback and formative assessment are rare (Frank, 2017). My hope in this paper is to put feedback at the center of teaching as a way of empowering teachers to take ownership over a central aspect of their work.

2 As will become clear, this paper is written from the standpoint of an American, and examples will be drawn from the American context. At the same time, every effort will be made to demonstrate how these ideas related to feedback might transcend that context.

3 Including, very importantly, problematising the very idea of an achievement gap and helpfully reframing it as a 'debt' (Ladson-Billings, 2006).

4 For example, I think it will be especially useful to think about how truthfulness helps us approach curriculum design and teaching controversial issues in the classroom.

5 Again, I will use UbD as a framework in this paper, but many other approaches to instructional planning will work here.

6 Retrieved from http://www.corestandards.org/ELA-Literacy/RL/9-10/

7 I see this as connected to David Hawkins's (1974) thinking on the teaching triangle. For an excellent recent discussion of Hawkins's work, see Rodgers (2020).

8 For a beautiful discussion of how a teacher uses feedback to connect with students, see Tovani (2011). For another inspiring discussion, see Berger (2003).

9 For an extremely interesting discussion, and one that hasn't received the attention in deserves in education (especially because it speaks directly to the practice of teaching), please see Potter (2002). 


\section{Jeff Frank}

\section{References}

Biesta, G. (2010). Good education in an age of measurement. Paradigm.

Biesta, G. (2012). Giving teaching back to education. Phenomenology \& Practice, 6(2), 35-49. https://doi.org/10.29173/pandpr 19860

Biesta, G., \& Stengel, B. (2016). Thinking philosophically about teaching. In D. H. Gitomer, \& C. A. Bell (Eds.), Handbook of research on teaching (5th ed., pp. 7-68). American Educational Research Association.

Berger, R. (2003). An ethic of excellence. Stenhouse.

Buchanan, A. (2018). Prisoners of misbelief: The epistemic conditions of freedom. In D. Schmidtz, \& C. E. Pavel (Eds.), The Oxford handbook of freedom (pp. 508-524). Oxford University Press.

Cochran-Smith, M. (2000). Blind vision: Unlearning racism in teacher education. Harvard Educational Review, 70(2), 157-190. https://doi.org/10.17763/haer. 70.2.e77x215054558564

Cooper, D. E. (2008). Teaching and truthfulness. Studies in Philosophy and Education, 27(2-3), 79-87. doi:10.1007/s11217-007-9091-x

Earl, L. (2003). Assessment as learning. Corwin.

Egelandsdal, K., \& Riese, H. (2020). Never mind the gap: Formative assessment confronted with Dewey's and Gadamer's concept of experience. European Journal of Education, 55(1), 3-14. doi:10.1111/ejed.12378

Frank, J. (2013). Mitigating against epistemic injustice in educational research. Educational Researcher, 42(7), 363-370. doi:10.3102/0013189X12457812

Frank, J. (2017). Bound to the mimetic or the transformative? Considering other possibilities. Education and Culture, 33(1), 23-40. doi:10.5703/educationculture. 33.1 .0023

Frank, J. (2020). Against technology-mediated personalized learning: Resources from John William Miller and Henry Bugbee to support parental resistance. Ethics and Education, 15(1), 98-112. doi:10.1080/17449642.2019.1700445

Frank, J. (2021). Belonging in college: John William Miller on liberal education's promise of freedom. Soundings, 104(2-3), 260-274. doi:10.5325/soundings. 104.2-3.0260

Frank, J., \& McDonough, J. (2020). Core practices and philosophy of education: Balancing effectiveness with goodness. Teachers College Record, 122(4), 1-22. https://eric.ed.gov/?id=EJ1268390

Fricker, M. (2020). Bernard Williams as a philosopher of ethical freedom. Canadian Journal of Philosophy, Early View, 1-15. doi:10.1017/can.2020.43

Hansen, D. T. (1993). From role to person: The moral layeredness of classroom teaching. American Educational Research Journal, 30(4), 651-674. doi:10.3102 $/ 00028312030004651$

Hansen, D. T. (1995). The call to teach. Teachers College Press.

Hansen, D. T. (2018). Bearing witness to the fusion of person and role in teaching. In N. Wahlström, D. Alvunger, \& D. Sundberg (Eds.), Teachers matter-But how? (pp. 7-23). Routledge.

Harber, K. D., Reeves, S., Gorman, J. L., Williams, C. H., Malin, J., \& Pennebaker, J. W. (2019). The conflicted language of interracial feedback. Journal of Educational Psychology, 111(7), 1220-1242. doi:10.1037/edu0000326

Harðarson, A. (2012). Why the aims of education cannot be settled. Journal of Philosophy of Education, 46(2), 223-235. doi:10.1111/j.1467-9752.2012.00847.x 
Harðarson, A. (2018). The teacher is a learner: Dewey on aims in education. Educational Philosophy and Theory, 50(5), 538-547. doi:10.1080/00131857.20 17.1395735

Hawkins, D. (1974). I, thou, it. In D. Hawkins (Ed.), The informed vision: Essays in teaching and learning (pp. 48-62). Agathon Press.

Jackson, P. W. (1990). Life in classrooms. New York: Teachers College Press. (Original work published 1968).

Ladson-Billing, G. (2006). From the achievement gap to the education debt. Educational Researcher, 35(7), 3-12. doi:10.3102/0013189X035007003

Lampert, M. (2001). Teaching with problems and the problems of teaching. Yale University Press.

Lear,J.(2009).UniversityofChicago:Aimsofeducationaddress. Retrievedfromhttps:// college.uchicago.edu/student-life/aims-education-address-2009-jonathan-lear

Martinez, M. R., \& McGrath, D. (2014). Deeper learning. New Press.

Mehta, J., \& Fine, S. (2019). In search of deeper learning. Harvard University Press.

Pendlebury, S. (2008). Accuracy, sincerity and capabilities in the practice of teaching. Studies in Philosophy and Education, 27(2-3), 173-183. doi:10.1007/ s11217-007-9088-5

Potter, N. N. (2002). How can I be trusted? Rowman and Littlefield.

Rauch, J. (2020). Trump's firehose of falsehood. Persuasion [online]. Retrieved from https://www.persuasion.community/p/trumps-firehose-of-falsehood

Ritchart, R. (2015). Creating cultures of thinking. Jossey-Bass.

Rodgers, C. (2020). The art of reflective teaching: practicing presence. Teachers College Press.

Rømer, T. A. (2019). A critique of John Hattie's theory of visible learning. Educational Philosophy and Theory, 51(6), 587-598. doi:10.1080/00131857.20 18.1488216

Santoro, D. (2011). Teaching's conscientious objectors. Teachers College Record, 113(12), 2670-2704. https://eric.ed.gov/?id=EJ988304

Santoro, D. (2018). Demoralized. Harvard Education Press.

Siegel, D., \& Bryson, T. (2018). The yes brain. Bantam Books.

Tovani, C. (2011). So what do they really know? Stenhouse.

Wiggins, G., \& McTighe, J. (2005). Understanding by design (2nd ed.). ASCD.

Williams, B. (2002). Truth and truthfulness. Princeton University Press. 